\title{
Comparative Physical Modes of Action of Azoxystrobin, Mancozeb, and Metalaxyl Against Plasmopara viticola (Grapevine Downy Mildew)
}

\author{
Francis P. Wong and Wayne F. Wilcox, Department of Plant Pathology, Cornell University, New York Agricultural \\ Experiment Station, Geneva, NY 14456
}

\begin{abstract}
Wong, F. P., and Wilcox, W. F. 2001. Comparative physical modes of action of azoxystrobin, mancozeb, and metalaxyl against Plasmopara viticola (grapevine downy mildew). Plant Dis. 85:649-656.

The physical modes of action of azoxystrobin, mancozeb, and metalaxyl were evaluated on grapevine seedlings using Plasmopara viticola as a model pathogen. The protectant, postinfection, postsymptom, translaminar, and vapor activities of azoxystrobin were evaluated at a rate of $250 \mu \mathrm{g} / \mathrm{ml}$. Azoxystrobin provided 100\% disease control when applied 1 to 5 days before inoculation. Postinfection applications of azoxystrobin had little effect on the incidence of disease, but colony area and sporulation from the resultant lesions was reduced by 47 and $96 \%$, respectively, relative to the check treatment when applied up to 5 days after inoculation. Postsymptom applications (6 days after inoculation) of azoxystrobin resulted in an 85\% mean reduction of resporulation from diseased tissue relative to the check when seedlings were evaluated 1 to 14 days after treatment. Translaminar activity was greatest when the upper surface of the leaf was treated 7 days before inoculation of the lower leaf surface ( $94 \%$ disease control). In contrast, control was $<50 \%$ when leaves were similarly inoculated 1 and 3 days after treatment. Vapor activity was not pronounced, providing maximum reductions of 5,11 , and $37 \%$, with regard to incidence, colony area, and sporulation, relative to the check when seedlings were treated 1 to 7 days before inoculating adjacent, untreated leaves. Comparatively, mancozeb $(1,790 \mu \mathrm{g} / \mathrm{ml})$ provided complete control of the disease when applied 1 to 5 days before inoculation, but showed little postinfection activity in reducing disease incidence, although it exhibited moderate to high antisporulant activity when applied in postinfection and postsymptom modes (mean reductions of 38 and $89 \%$, respectively, compared with the check treatments). Metalaxyl (260 $\mu \mathrm{g} / \mathrm{ml}$ ) also provided complete control of the disease when used in protectant mode, and also when applied 1 day after inoculation. Applications at 3 to 5 days after inoculation provided substantial reductions in disease severity and sporulation (mean reductions of 46 and $94 \%$, respectively, compared with the check treatments), and postsymptom applications resulted in a mean $84 \%$ reduction in resporulation. Collectively, the results of this study illustrate the unique physical modes of action for azoxystrobin in comparison to that of two traditional protectant and systemic fungicides, and provide information on how azoxystrobin and other strobilurin fungicides with similar physical modes of action should be best used in disease management programs.
\end{abstract}

Plasmopara viticola (Berk. \& Curt.) Berl. \& Toni., the causal agent of grapevine downy mildew, is a highly destructive pathogen on cultivated grapevine worldwide, especially in areas where warm, wet weather occurs during the production season (10). The primary component of virtually all commercial management programs for this disease is the use of organic and inorganic fungicides. Among the fungicides recently made available for downy mildew control are the strobilurins, a new class of crop protection chemicals currently used for the management of a wide range of fungal diseases. These are unique in the sense that they are the first modern,

Corresponding author: F. P. Wong

E-mail: wongf@basf-corp.com

Accepted for publication 6 March 2001.

Publication no. D-2001-0419-01R

(C) 2001 The American Phytopathological Society synthetic, site-specific fungicides to provide commercially acceptable control of fungal pathogens from all three major divisions of fungi: Oomycota, Ascomycota, and Basidiomycota $(1,2,7,9,11,14)$.

Although the biochemical mode of action for these fungicides is well characterized $(3,5,18)$, there is relatively little published data on their physical modes of action. This term, as described by Szkolnik (17) and elaborated upon by Köller (12), is used in reference to the observable effects of a fungicide on the host-pathogen interaction with respect to the timing and/or placement of the fungicide application, e.g., protectant, postinfection (curative), postsymptom, and vapor activities. The strobilurin fungicides also exhibit what has been termed translaminar activity $(6,7,27)$, defined as the ability of a fungicide to penetrate through leaf tissue from a sprayed to an unsprayed lamina at concentrations sufficient to provide disease control on the unsprayed side. Understanding the extent of physical modes of action for individual fungicides is essential for optimizing their use in disease management programs.

The strobilurin-pathogen interactions best described in the literature include azoxystrobin against Pseudoperonospora cubensis (9), Puccinia recondita (6), and Sphaerotheca fuliginea (9); and kresoximmethyl against Erysiphe graminis var. tritici $(7,8)$, Puccinia recondita $(7,8)$, Uncinula necator $(7,13)$, Uromyces appendiculatus (7), and Venturia inaequalis $(7,8)$. Many of these reports include some information concerning physical modes of action, although the details of experimental procedures and/or quantitative data relative to this topic are frequently incomplete or lacking. Furthermore, there are no detailed reports concerning the physical modes of action for any of the strobilurin fungicides against the intercellular, oomycete pathogen, $P$. viticola.

Therefore, the objective of this study was to evaluate the physical modes of action (protectant, postinfection, postsymptom, translaminar, and vapor activities) of azoxystrobin against $P$. viticola, and to compare these with the activities of standard fungicides (mancozeb and metalaxyl), whose physical modes of action are generally well understood $(17,19)$, using a seedling bioassay system. Azoxystrobin was chosen due to its well-characterized level of intrinsic activity against $P$. viticola (25), its effectiveness for the control of grapevine downy mildew in field trials (20-23), and its importance for disease control programs in the eastern United States, where it is the first fungicide available that provides commercially acceptable control of Guignardia bidwellii, $P$. viticola, and $U$. necator, the three most economically important pathogens of grapes in this region.

\section{MATERIALS AND METHODS}

Fungicides. Commercial formulations of azoxystrobin (Abound, $2.08 \mathrm{~F}$, Zeneca Ag Products, Richmond, CA ), mancozeb (Dithane 75DF, Rohm and Haas, Philadelphia, PA), and metalaxyl (Ridomil 2E, Novartis Crop Protection, Greensboro, NC) were used in all assays unless noted otherwise. Fungicides were applied at rates equivalent to those used in dilute (936 liters/ha) applications under field conditions. For each experiment, formulated product was mixed in $50 \mathrm{ml}$ of $\mathrm{dH}_{2} \mathrm{O}$ to obtain final fungicide concentrations of $250 \mu \mathrm{g} / \mathrm{ml}$ for azoxystrobin, $1,790 \mu \mathrm{g} / \mathrm{ml}$ for mancozeb, and $260 \mu \mathrm{g} / \mathrm{ml}$ for metalaxyl. 
For seedling bioassays, unless otherwise noted, leaves were sprayed until runoff on both the upper and lower surfaces, using a modified paint sprayer attached to a 50-ml centrifuge tube containing the fungicide solutions or $\mathrm{dH}_{2} \mathrm{O}$ (check treatment), operating at a pressure of $206 \mathrm{kPa}$. The apparatus was cleaned thoroughly between the different fungicide treatments by rinsing the exterior under running water and then running approximately $50 \mathrm{ml}$ of a dilute solution of liquid soap and $\mathrm{dH}_{2} \mathrm{O}$ through the sprayer, followed by $50 \mathrm{ml}$ of $50 \%$ acetone and then $50 \mathrm{ml}$ of $\mathrm{dH}_{2} \mathrm{O}$.

Collection and maintenance of $P$. viticola. A single isolate of $P$. viticola (DM15) was used for all assays, unless noted otherwise. This isolate was in the top quartile of a $P$. viticola population previously characterized (25) for sensitivity to azoxystrobin $\left(\mathrm{DM}-15, \mathrm{ED}_{50}=0.56 \mu \mathrm{g} / \mathrm{ml}\right.$, mean baseline $\mathrm{ED}_{50}=0.24 \mu \mathrm{g} / \mathrm{ml}$ ). It was maintained in petri dishes on greenhouse-grown Vitis vinifera cv. Gewürztraminer leaf sections (approximately $30 \times 60 \mathrm{~mm}$ ), with weekly transfers to fresh tissue, as described previously (25). An additional isolate $\left(\mathrm{AR}-1, \mathrm{ED}_{50}=0.35 \mu \mathrm{g} / \mathrm{ml}\right)$ was maintained in the same manner for use in oospore-formation experiments. To obtain adequate amounts of inoculum for the experiments, isolates were amplified by inoculating several Gewürztraminer leaf sections 1 week beforehand (25).

Seedlings. Stratified, open-pollinated seeds of $V$. vinifera $\mathrm{cv}$. Riesling were germinated under continual mist in a greenhouse at $30^{\circ} \mathrm{C}$ and transplanted subsequently into $6.4-\mathrm{cm}$ square pots filled with a mixture of three volumes Cornell Mix and one volume sand. Seedlings were grown at $20^{\circ} \mathrm{C}$ and $80 \%$ relative humidity $(\mathrm{RH})$ in a pathogen-free growth chamber (Percival, Perry, LA) with alternating 12 -h periods of fluorescent light and darkness, unless otherwise noted. Seedlings that were approximately 6 weeks old, having three fully expanded leaves (greater than $2.5 \mathrm{~cm}$ in width), were used in the bioassays. Subsequent to experimental fungicide treatments, seedlings were maintained in a separate growth chamber at $20^{\circ} \mathrm{C}$ and $80 \% \mathrm{RH}$.

Seedling bioassays. Inoculation of seedlings. Unless otherwise stated, seedlings were suspended upside down in a walk-in mist chamber at $20^{\circ} \mathrm{C}$ immediately before inoculation. The chamber was allowed to mist for a minimum of $1 \mathrm{~h}$ before placing the seedlings inside, to allow it to equilibrate. A single 10- $\mu$ l drop containing a suspension of $2 \times 10^{4}$ sporangia of isolate DM-15 per milliliter was applied to each of the four quadrats on the underside of each of the three fully expanded leaves per seedling. The inoculum was obtained by placing two to three sporulating leaf sections, cut into approximately $10-\mathrm{mm}$-wide pieces, in a 15-ml screw-top centrifuge tube containing $5 \mathrm{ml}$ of sterile $\mathrm{dH}_{2} \mathrm{O}$, and briefly vortexing for $15 \mathrm{~s}$. This initial con- centration of sporangia was determined with the aid of a hemacytometer and diluted with sterile $\mathrm{dH}_{2} \mathrm{O}$ to obtain the appropriate inoculum concentration. Inoculated seedlings were maintained in the mist chamber overnight in darkness, then removed and allowed to dry for approximately $2 \mathrm{~h}$ at room temperature before they were returned to the appropriate growth chamber.

Five days after inoculation, seedlings were placed into the mist chamber and incubated overnight in darkness at $20^{\circ} \mathrm{C}$, to allow for the completion of disease development and promote the formation of sporangia. Disease was evaluated 6 days after inoculation based upon disease incidence, colony area, and sporulation intensity. Disease incidence was measured as the number of lesions that developed per seedling. Colony area was calculated as the surface area of the individual lesions formed, based upon the average of three measurements of diameters across each generally circular lesion, and applying the formula $\mathrm{SA}=\pi(\text { diameter } / 2)^{2}$. Sporulation intensity was determined by removing the sporulating areas of each leaf with a scalpel and forceps, and vortexing these excisions in $2 \mathrm{ml}$ of a $0.05 \%$ solution of Tween 20 for $30 \mathrm{~s}$ in a $15-\mathrm{ml}$ screw-top centrifuge tube. Sporangia concentrations were measured with the aid of a hemacytometer, using the average of three repeated measurements per sample.

Statistical analyses (ANOVA, multiple comparisons, and linear regression) were performed using MINITAB (v. 12.10, State College, PA) and SAS (v. 6.0, SAS Institute, Cary NC). The means of each experimental run of six replicate seedlings per treatment were used for the statistical analyses. Colony area data were normalized using a square-root transformation, and sporulation data were normalized using the $\log _{10}(y+1)$ transformation function. The general linear model was used for analysis of variance, and either DuncanWaller groupings or Dunnett's multiple comparisons were used for multiple comparisons.

Protectant and postinfection activities. Seedlings were sprayed with either azoxystrobin, mancozeb, or metalaxyl at 1,3 , or 5 days before inoculation with $P$. viticola, in order to determine the protectant activities of these fungicides. Similarly, seedlings were sprayed 1,3 , or 5 days after inoculation to determine postinfection activities. For each experimental run, the check treatment consisted of seedlings sprayed only with $\mathrm{dH}_{2} \mathrm{O} 1$ day before inoculation. Seedlings were allowed to dry at room temperature, and afterward they were moved to a growth chamber. Seedlings subjected to individual treatments were spatially separated in the growth chamber by a minimum of $30 \mathrm{~cm}$, to minimize cross-treatment interference. Fungicides were tested in separate experiments, and each set of these was performed three times, using six replicate seedlings per treatment. Analysis of variance and multiple comparisons were performed as described above, analyzing the effect of each fungicide separately.

Postsymptom activity. To evaluate the ability of the fungicides to arrest resporulation from diseased tissue, and to identify the duration of effectiveness when applied in this manner, seedlings were inoculated and induced to sporulate 5 days after inoculation, as described above. Six days after inoculation, sporangia were removed from the leaf underside by flushing the tissue with a steady stream of $\mathrm{dH}_{2} \mathrm{O}$ (approximately $10 \mathrm{ml} / \mathrm{s}$ for $10 \mathrm{~s}$ for each leaf). Seedlings were allowed to dry at room temperature for $2 \mathrm{~h}$, then sprayed with fungicide solutions (or $\mathrm{dH}_{2} \mathrm{O}$ ) and again allowed to dry at room temperature for $2 \mathrm{~h}$. Then, seedlings were moved to a growth chamber and either $1,3,5,7,10$, or 14 days later, sets of six seedlings for each time point were placed into the mist chamber to induce resporulation. Twenty-four hours after placement into the mist chamber, one infected leaf per seedling, each of approximately uniform size and developmental stage, was removed, and sporulation intensity was quantified as described above. The experiment was run three times, using six replicate seedlings per treatment. Analysis of variance and regression analysis were performed as described above.

Translaminar activity. To evaluate translaminar activity, the adaxial surface of the second fully expanded leaf on each seedling was treated by floating the attached, intact leaves for $5 \mathrm{~min}$ on $15 \mathrm{ml}$ of the appropriate fungicide solution (or $\mathrm{dH}_{2} \mathrm{O}$ for the check treatment) contained in 60-mm-diameter petri dishes. Surface tension prevented the solutions from contacting the abaxial leaf surface, and special care was taken to prevent any incidental contact of the abaxial surface with fungicides. Leaves were allowed to dry for 10 min at room temperature before returning them to the growth chamber, then they were inoculated with $P$. viticola as described above, either $1,3,5$, or 7 days after treatment ( 1 day for the $\mathrm{dH}_{2} \mathrm{O}$ check). Five days postinoculation, seedlings were placed into the mist chamber, and $24 \mathrm{~h}$ later, incidence, colony expansion, and sporulation intensity were evaluated as described above. The experiment was performed a total of three times, using six replicate seedlings per treatment. Analysis of variance and regression analysis were performed as described above.

Vapor activity of azoxystrobin. To test the vapor redistribution to tissues distal to the point of application, the second fully expanded leaves (distal to the shoot tip) of individual seedlings were treated with azoxystrobin (or $\mathrm{dH}_{2} \mathrm{O} 1$ day before inoculation), as described for the translaminar 
activity assays. Treated seedlings were maintained inside the growth chamber at $20^{\circ} \mathrm{C}, 80 \% \mathrm{RH}$, then leaves one position above the treated leaf were inoculated either $1,3,5$, or 7 days after treatment. Seedlings were incubated and evaluated for disease 6 days after inoculation, as described previously. To assay the vapor activity of azoxystrobin under optimal conditions, the experiment was modified by transferring fungicide-treated seedlings to translucent plastic boxes $(51 \mathrm{~cm}$ wide $x$ $102 \mathrm{~cm}$ long $\times 30 \mathrm{~cm}$ tall) with tight fitting lids (Rubbermaid, Wooster, $\mathrm{OH}$ ), where they were maintained for the duration of the experiment (except for the overnight period in the mist chamber following inoculation). Seedlings were evaluated for disease 6 days after inoculation, as described previously. Both sets of experiments were performed a total of three times, using six replicate seedlings per treatment in each run. Analysis of variance and regression analysis were performed as described above.

Effect of postinfection and postsymptom fungicide applications on oospore formation. To test the ability of azoxystrobin, mancozeb, and metalaxyl to retard or halt the activity of $P$. viticola once it had become established within the leaf tissue, the effect of postinfection and postsymptom applications of fungicides on oospore formation was evaluated. Using standard procedures, seedlings were inoculated with a mixture containing equal ratios of two isolates of P. viticola (DM-15 and AR-1), which represent opposite mating types of the fungus and had produced oospores in previous experiments when co-inoculated onto detached leaf disks (24). To evaluate postinfection applications, seedlings were treated with fungicides (or $\mathrm{dH}_{2} \mathrm{O}$ ) 3 days after inoculation. Five days after inoculation, seedlings were placed in the mist chamber overnight to allow for the completion of the normal, secondary disease cycle for $P$. viticola, as described previously. Seedlings were then transferred to a growth chamber maintained at $12^{\circ} \mathrm{C}$ and $80 \% \mathrm{RH}$, with alternating 12 -h periods of darkness and fluorescent light, to promote oospore formation (15). The experiment was performed three times using six replicate seedlings per treatment.

To evaluate postsymptom activities, inoculated seedlings were returned to the mist chamber 5 days after inoculation, then they were removed the following day and treated with fungicides (or $\mathrm{dH}_{2} \mathrm{O}$ ) after they had dried. Seedlings were allowed to re-dry for $2 \mathrm{~h}$ after treatment, then they were transferred to a growth chamber maintained at $12^{\circ} \mathrm{C}, 80 \% \mathrm{RH}$, with alternating $12-\mathrm{h}$ periods of darkness and fluorescent light. This experiment was also performed three times using six replicate seedlings per treatment.

For both the postinfection and postsymptom experiments, seedlings were
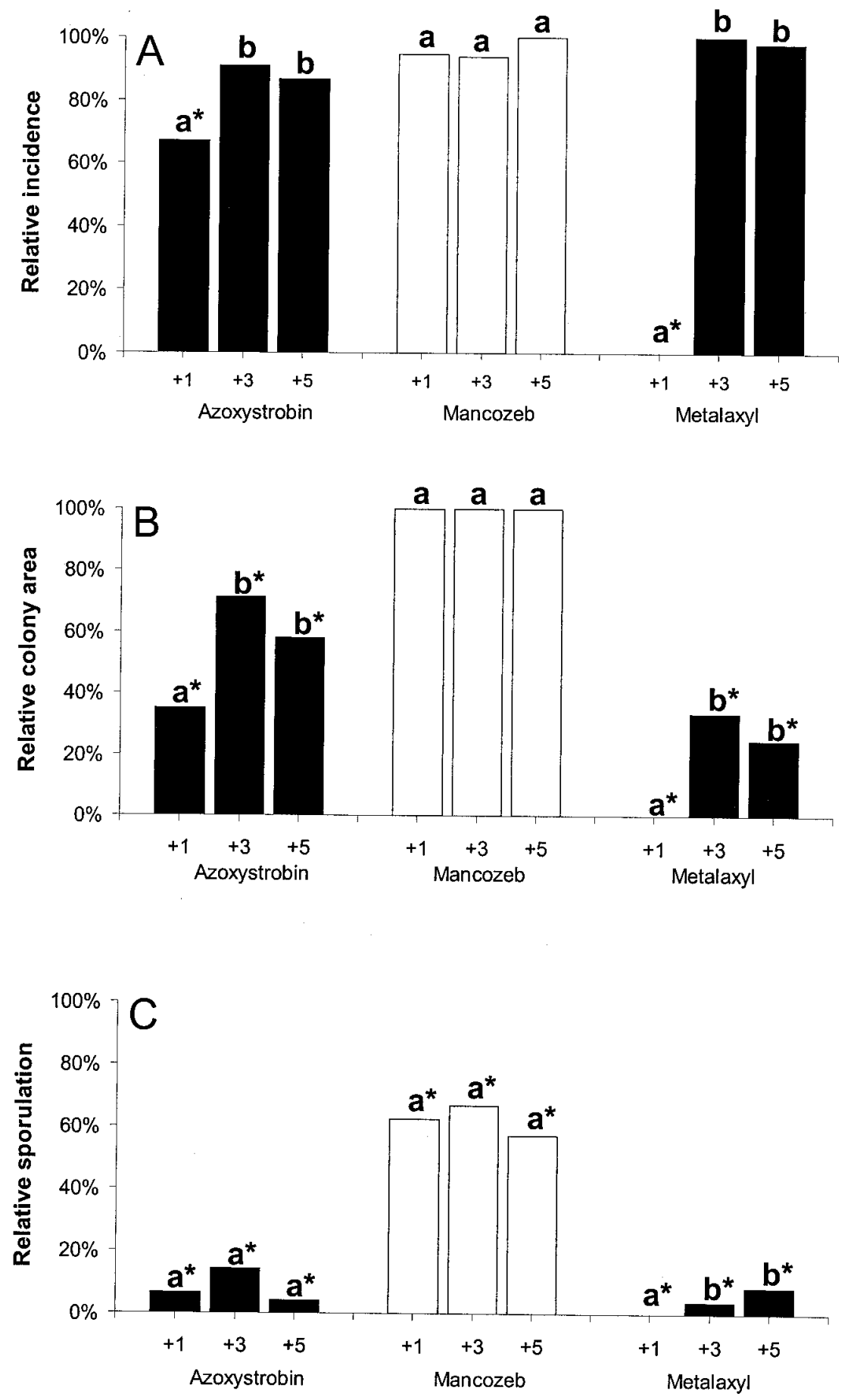

\section{Application timing (days relative to inoculation) and treatment}

Fig. 1. Postinfection activities of azoxystrobin, mancozeb, and metalaxyl versus Plasmopara viticola. For each test, one fungicide was sprayed onto six individual Vitis vinifera cv. Riesling seedlings per treatment either 1,3 , or 5 days after inoculation. Disease was assessed 6 days after inoculation following overnight incubation in darkness and high humidity to promote completion of the disease cycle. The experiment was performed three times for each fungicide. A, Disease incidence, expressed as the percentage of sporulating lesions per seedling relative to the $\mathrm{dH}_{2} \mathrm{O}$ check treatment. $\mathbf{B}$, Colony area, expressed as percentage of the surface area of lesions on fungicide-treated seedlings relative to those in the $\mathrm{dH}_{2} \mathrm{O}$ check treatment. C, Sporulation, expressed as percentage of sporangia produced relative to the $\mathrm{dH}_{2} \mathrm{O}$ check treatment. Within each fungicide group, columns designated with different letters are significantly different by the Duncan-Waller grouping $(P=0.05)$, and columns designated by $(*)$ were significantly different from the check treatment (Dunnett's multiple comparison, $P=0.05)$. 
removed from the growth chamber after 14 days of incubation at $12^{\circ} \mathrm{C}$. Previous experiments showed that oospore formation under these conditions required approximately 10 days (24). All of the lesions that had formed on seedlings were removed, using a 10-mm-diameter cork borer. In cases where the generally circular lesions were greater than $10 \mathrm{~mm}$ in diameter, the center of the lesion was removed. All leaf disks from each seedling were placed into ing $10 \mathrm{ml}$ of $95 \%$ ethanol for $72 \mathrm{~h}$ to clear the tissue in order to aid in the detection of oospores. To quantify the number of oospores formed, four cleared leaf disks were chosen arbitrarily from each sample and rinsed in $\mathrm{dH}_{2} \mathrm{O}$. The total number of oospores formed in each leaf disk was counted using light microscopy at $\times 100$ magnification. Analysis of variance and multiple comparisons were performed as described above, using the $\log _{10}(y+1)$ transformed values of the number of oospores formed to normalize the data.

\section{RESULTS}

Protectant and postinfection activities. All three fungicides provided $100 \%$ disease control when applied in protectant mode from 1 to 5 days before inoculation. However, there were marked differences in disease control when the fungicides were applied after inoculation with $P$. viticola. For example, azoxystrobin provided modest $(33 \%)$ reductions in disease incidence relative to the check treatment when applied 1 day postinoculation, whereas mancozeb provided no control and metalaxyl provided complete control (Fig. 1A). Howa 15 -ml screw-top centrifuge tube contain-

ever, none of the fungicides provided significant control of disease incidence when applied 3 or 5 days after inoculation (Fig. 1A). Azoxystrobin also substantially restricted the development of those infections that did occur following postinoculation treatments, reducing the mean lesion area relative to the checks by 72,33 , and $45 \%$ when applied 1, 3, and 5 days after inoculation, respectively. As with disease incidence, these reductions were greater than those provided by mancozeb, which had no significant effect on lesion development, but less than those provided in separate tests by comparable sprays with metalaxyl (Fig. 1B). The most pronounced postinfection activity provided by azoxystrobin was with respect to sporulation from those lesions that developed subsequently, which was reduced by 86 to $96 \%$ relative to the check, with no significant difference in this effect among any of the three application timings. Metalaxyl similarly inhibited sporulation from those lesions that developed following the 3- and 5-day postinoculation sprays, whereas mancozeb reduced sporulation by only 33 to $43 \%$ across the three timings (Fig. 1C).

Postsymptom activity. All three fungicides provided pronounced and basically equivalent postsymptom activity when seedlings were evaluated from 1 to 14 days after fungicide treatment. Resporulation from fungicide-treated leaves was reduced by 77 to $98 \%$ relative to seedlings treated with $\mathrm{dH}_{2} \mathrm{O}$, depending on the individual treatment; in general, the greatest percent reductions occurred following the 10- and 14-day incubation periods (Fig. 2). The mean numbers of sporangia recovered

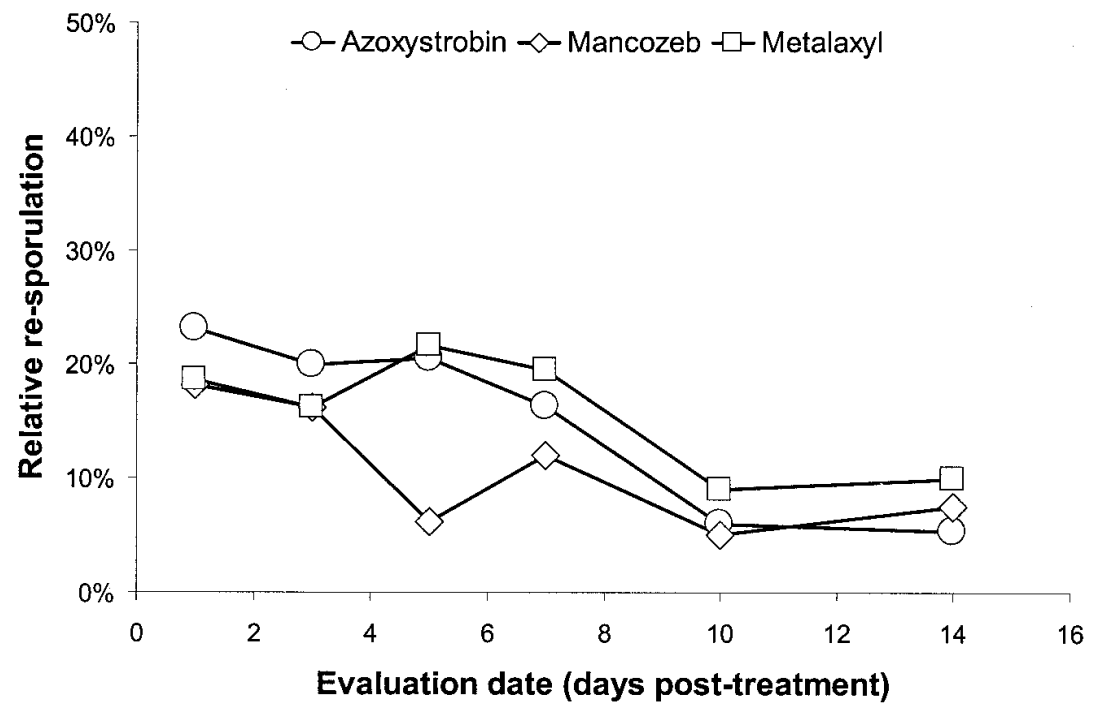

Fig. 2. Postsymptom activity of azoxystrobin, mancozeb, and metalaxyl versus Plasmopara viticola. For each test, six individual Vitis vinifera cv. Riesling seedlings were treated with fungicides 6 days after inoculation and following overnight incubation in darkness and high humidity to promote sporangium formation. These initial sporangia were flushed from the leaves immediately before fungicide applications, then re-sporulation was assessed $1,3,5,7,10$, or 14 days later, following an additional overnight incubation period in darkness and high humidity. Resporulation is expressed as percentage of sporangia produced relative to the $\mathrm{H}_{2} \mathrm{O}$ check treatment mean values for the repeated runs of the experiment. from fungicide-treated seedlings were significantly different from the check treatment $(P<0.001)$ but equivalent to each other regardless of evaluation date $(P$ $=0.23$ ).

Translaminar activity. Applications of azoxystrobin to the upper leaf surface resulted in a reduction in disease following inoculation of the lower leaf surface, the magnitude of which increased in proportion to the time elapsed between treatment and inoculation. Disease development on treated seedlings was significantly different from the $\mathrm{dH}_{2} \mathrm{O}$-treated checks at all time points tested $(P<0.001)$, and the response was linear over time for reductions in incidence $(P<0.001)$, colony area $(P<0.001)$, and sporulation intensity $(P=$ $0.02)$. For example, reductions in disease incidence (relative to the check treatment) increased from $57 \%$ when the fungicide was applied 1 day before inoculation to 94\% when applications were made 7 days before inoculation (Fig. 3A), with similar reductions (63 to 92\%) observed for the effect on colony area (Fig. 3B). As found with the assays for postinfection activity, translaminar activity was expressed most strongly with respect to its effect on the production of sporangia from the resultant lesions, i.e., sporulation was reduced by 93 to $100 \%$ for the four azoxystrobin treatments (Fig. 3C). In comparison, mancozeb had no effect on the development of downy mildew when applied in this manner, whereas metalaxyl provided complete control (Fig. 3A to C).

Vapor activity of azoxystrobin. Apparent vapor activity of azoxystrobin on treated seedlings resulted in a timedependent reduction in disease development with maximum reductions occurring when they were inoculated 7 days after treatment. Under optimal conditions, there was a linear response for disease development over the four time points tested with regard to disease incidence $(P=0.03)$, colony area $(P<0.001)$, and sporulation $(P$ $<0.001)$. The effect on disease incidence was small, ranging from a 0 to $14 \%$ reduction from when seedlings were inoculated 1 day to 7 days after treatment (Fig. 4A). Colony area and sporulation were reduced by 52 and $81 \%$ relative to the check, respectively, when seedlings were inoculated 7 days after treatment (Fig. 4B and C).

For seedlings tested under open conditions (when they were not placed into closed plastic boxes), the effect of the vapor activity of azoxystrobin was less pronounced. There was no significant effect on disease incidence over the time points tested $(P=$ 0.83 ), but linear reductions in colony area and sporulation over time were observed $(P$ $=0.02$ and 0.004, respectively) (Fig. 4B and C). The strongest effects on both colony area and sporulation occurred (reductions of 11 and $37 \%$, relative to the check, respectively) when seedlings were inoculated 7 days after treatment. 
Effects of postinfection and postsymptom fungicide applications on oospore formation. The assay used to determine the effect of fungicides on oospore formation produced variable results, with no significant differences detected among treatments $(P=0.09$ and 0.33 for the postinoculation and postsymptom assays, respectively). Nevertheless, the mean number of oospores detected following treatment with azoxystrobin was reduced by $41 \%$ relative to the check in the postinoculation assay ( $P=0.07$, Dunnett's multiple comparisons) and by $53 \%$ in the postsymptom assays $(P=0.82)$ (Fig. 5). In comparison, oospore numbers were reduced by 53 and $29 \%(P=0.08$ and 0.73 , respectively) following treatment with metalaxyl in these respective assays, whereas reductions were $37 \%(P=0.09)$ and $0 \%$ for mancozeb, respectively (Fig. $5)$.

\section{DISCUSSION}

It is apparent from the results of this study that the primary physical mode of action for azoxystrobin against $P$. viticola is that of a protectant fungicide with strong antisporulant activity. Azoxystrobin provided complete control of downy mildew when applied up to 5 days before inoculation, although the persistence of protective activity was not tested beyond this duration. In contrast, postinfection applications of azoxystrobin had only modest to negligible effects on the subsequent development of $P$. viticola lesions, providing a greater inhibition of disease severity (colony area) than of disease incidence. However, postinfection and postsymptom applications profoundly limited sporulation of the fungus from these lesions. Based on these results, we suggest that azoxystrobin controls $P$. viticola primarily on the surface of treated tissues, by (i) preventing infections via an inhibition of sporangium and/or zoospore germination (26) and (ii) restricting the production of secondary inoculum (sporangia) from those lesions that do develop, perhaps as the pathogen encounters the fungicide when it erupts through the treated zone during the sporulation process.

In addition to these surface phenomena, it appears that azoxystrobin also provides some modest but measurable activity against $P$. viticola within leaf tissues. This conclusion is supported not only by the above-mentioned results from our postinfection assays, but also by those from our previous study (25), in which we noted that relatively low concentrations of azoxystrobin similarly restricted the expansion of $P$. viticola lesions that were otherwise able to form within treated leaf disks. Although the mechanism governing this relationship is uncertain, it is possible that limited amounts of the fungicide might diffuse from the cuticle into the leaf (6) at concentrations sufficient to restrict growth of the fungus yet too low to substantially eliminate it. Results from the oosporeformation assay, although variable and inconclusive, are nevertheless consistent with this hypothesis.
Although oospore formation can be a viable method for examining the activity of fungicides within leaf tissue against $P$. viticola, as reported in a similar study on dimethomorph (4), the test used in this
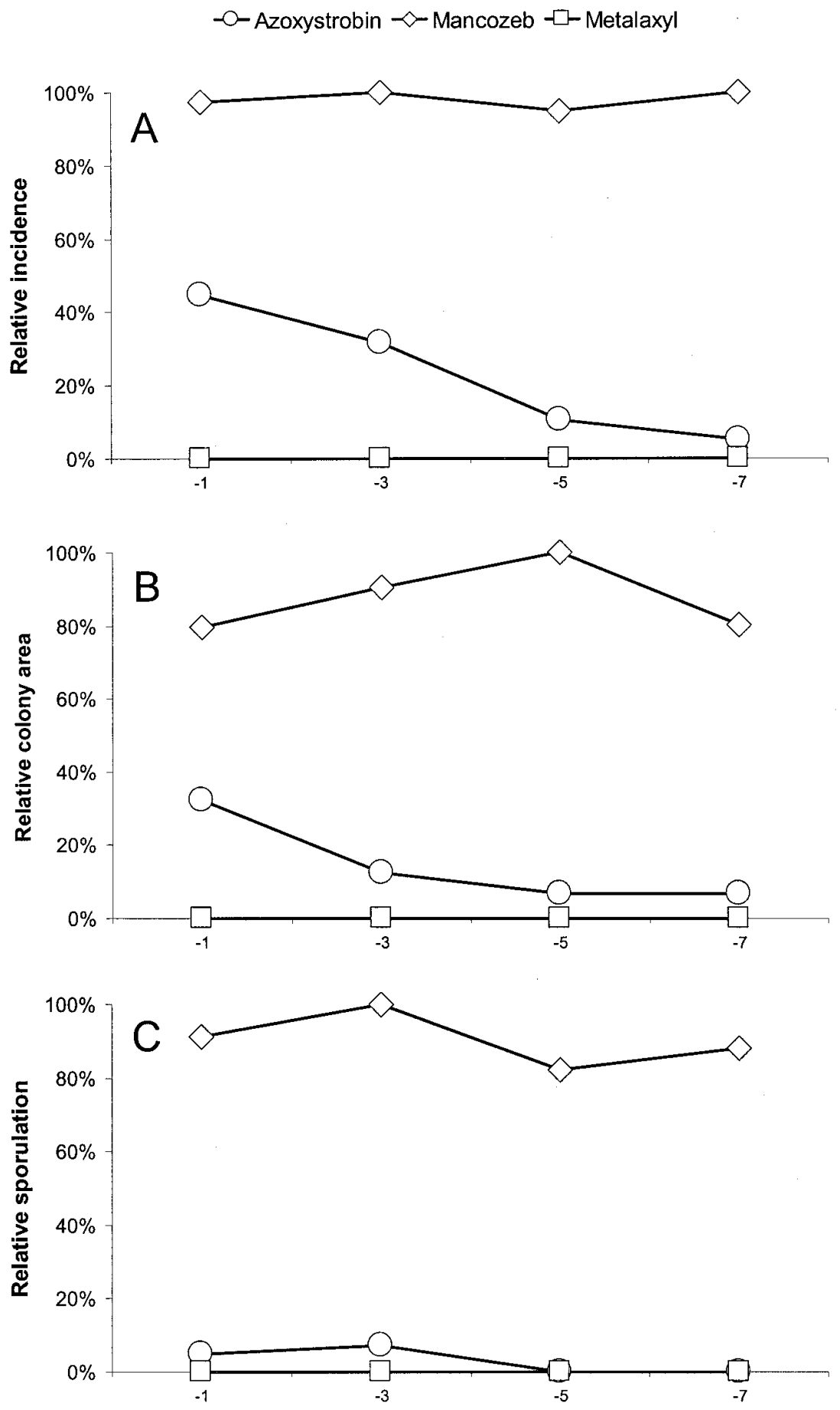

Application timing (days relative to inoculation)

Fig. 3. Translaminar activity of azoxystrobin, mancozeb, and metalaxyl versus Plasmopara viticola. For each test, six individual Vitis vinifera cv. Riesling seedlings were treated with fungicides on the adaxial surface of the second fully expanded leaves either 1,3,5, or 7 days before inoculation of the abaxial leaf surface. The test was performed three times for each fungicide. A, Disease incidence, expressed as percentage of sporulating lesions per seedling relative to the $\mathrm{dH}_{2} \mathrm{O}$ check treatment. $\mathbf{B}$, Colony area, expressed as percentage of the surface area of lesions on fungicide-treated seedlings relative to those in the $\mathrm{dH}_{2} \mathrm{O}$ check treatment. $\mathbf{C}$, Sporulation, expressed as percentage of sporangia produced relative to the $\mathrm{dH}_{2} \mathrm{O}$ check treatment. 
study was not reliable enough to effectively detect such differences between the fungicides tested in this study. Changes in methodologies to produce oospores more uniformly in planta would be needed to use this type of assay to produce clear results. Nevertheless, the results suggest that even a highly systemic fungicide (metalaxyl in
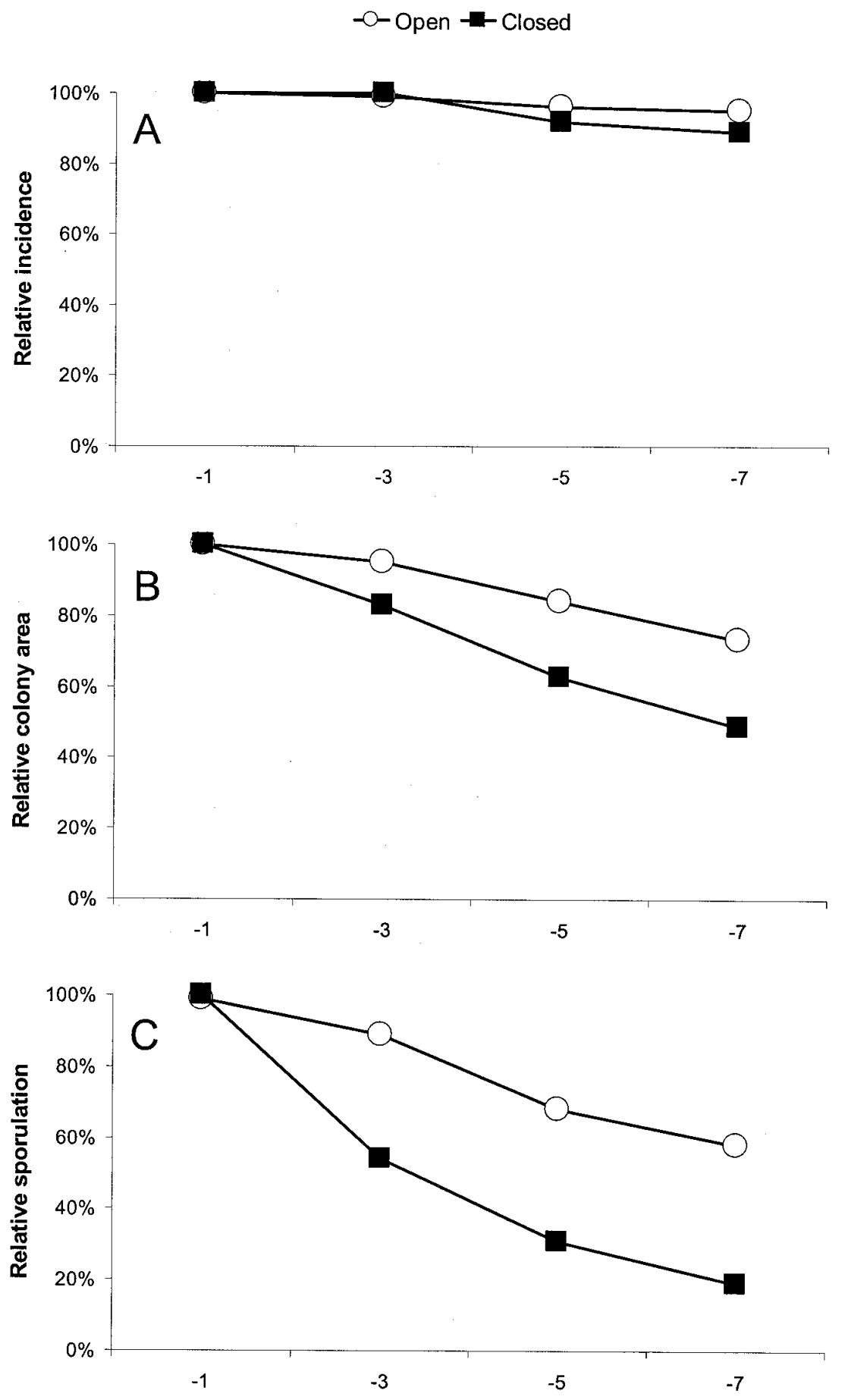

Application timing (relative to inoculation)

Fig. 4. Vapor activity of azoxystrobin versus Plasmopara viticola. For each test, the fungicide (or $\mathrm{dH}_{2} \mathrm{O}$ ) was applied to the adaxial surface of the second fully expanded leaves of six individual Vitis vinifera $\mathrm{cv}$. Riesling seedlings either 1, 3, 5, or 7 days before inoculation of the leaf one position above each treated leaf. In separate tests, treated seedlings were kept in either open or closed conditions after fungicide treatment. The test was performed three times under both conditions. A, Disease incidence, expressed as percentage of sporulating lesions per seedling relative to the $\mathrm{dH}_{2} \mathrm{O}$ check treatment. B, Colony area, expressed as percentage of the surface area of lesions on fungicide-treated seedlings relative to those in the $\mathrm{dH}_{2} \mathrm{O}$ check treatment. $\mathbf{C}$, Sporulation, expressed as percentage of sporangia produced relative to the $\mathrm{dH}_{2} \mathrm{O}$ check treatment.

this case) cannot completely eradicate this fungus after it has become well established inside the leaf tissue. Practically, this underlines the concept that "eradicant" use of fungicides has its limitations, and this mode of application should be minimized under field conditions for the most effective control of fungal plant pathogens.

Additional evidence for limited movement of azoxystrobin through treated leaf tissues was provided in the tests for translaminar activity, i.e., the extent of disease control increased directly as a function of the time elapsed between treatment of the adaxial lamina and subsequent inoculation of the abaxial, culminating in virtually complete control when inoculation was delayed until 7 days after treatment. This suggests that azoxystrobin may be diffusing through the leaf from the treated surface and accumulating in the cuticle of the untreated surface at concentrations sufficient to inhibit the initiation of infection. Alternatively, the fungicide may be accumulating over time within the leaf until its concentration is high enough to inhibit the development of the fungus shortly after it penetrates. Interestingly, two characteristics of the strobilurin fungicides are their inhibition of mitochondrial respiration in both fungal and nonfungal organisms and their rapid detoxification in the cytoplasm of most nonfungal eukaryotic cells (16). Thus, although the route of azoxystrobin movement that we observed is unclear, it seems likely to be through intercellular spaces rather than directly through the living cells of the leaf. Both microscopic studies and quantitative chemical analyses might help to further elucidate the actual site of action for translaminar activity. Regardless of the mechanism, this activity has practical implications with respect to disease control under field conditions should only one leaf surface be adequately sprayed.

Although the vapor activity of azoxystrobin contributed to a modest reduction in disease development, this activity was substantially more pronounced within a small, tightly closed plastic box than within a larger and better-ventilated growth chamber. Considering that even such an "open" growth chamber provided less opportunity for the dissipation of vapors than would be expected under field conditions, it seems unlikely that vapor activity is a major component of the control that azoxystrobin can exert outdoors against $P$. viticola in typical vineyards. These results emphasize the need to develop appropriate methodologies for evaluating the vapor activities of various fungicides, in order to avoid overemphasizing their impact under common agricultural conditions.

The antisporulant properties of metalaxyl versus $P$. viticola were similar to those reported by Wicks and Lee (19). Furthermore, the complete and rapid control of $P$. viticola provided by the fungicide 
in the translaminar assay, its excellent protective activity, and its pronounced but temporally restricted postinfection activity were consistent with expectations for a known systemic compound with a long history of efficacy against this pathogen. Nevertheless, to our knowledge, this is the first study to compare and quantify this entire range of physical modes of activity for metalaxyl (or its presently commercial enantiomer, mefanoxam) against a downy mildew. Similarly consistent with expectations for mancozeb, a traditional protectant fungicide (17) retained on the leaf surface, was its excellent protective activity coupled with a complete lack of effect on lesion development when examined in the translaminar and postinfection assays. However, its modest but significant antisporulant activity in the postinfection assay and its pronounced suppression of resporulation in the postsymptom assay exceeded those found in previous studies of the activity of this fungicide versus both $P$. viticola (19) and V. inaequalis (17).

In our tests, azoxystrobin provided protective activity against $P$. viticola that was equivalent to that provided by metalaxyl and mancozeb, but postinfection activity that was intermediate between the two. Clearly, azoxystrobin does not provide sufficient postinfection control of lesion development that it should be used as a curative fungicide by design, e.g., in response to a recently concluded infection period identified by a disease forecasting model. However, its pronounced antisporulant activities may contribute to control of secondary disease cycles and attendant epidemic development, thereby augmenting its protective activity when used within a disease management program. For instance, in a recent field trial (22), azoxystrobin and mancozeb each provided vir- tually complete control of cluster infections when applied four times at 2week intervals throughout the period of susceptibility to $P$. viticola. However, control (relative to the untreated check) was reduced to 83 and $29 \%$, respectively, when the first and final sprays were omitted, perhaps reflecting, in part, the relative abilities of these two fungicides to suppress secondary disease spread.

The azoxystrobin- $P$. viticola interaction described by this study is the first detailed investigation of the physical mode of action of a strobilurin fungicide against an intercellular Oomycete pathogen and may serve as a model for other interactions involving similar fungicides and pathogens. A similar study of physical modes of action for kresoxim-methyl against Puccinia recondita, $U$. necator, and Venturia inaequalis (8) indicated clear differences in activity against these three pathogens. Thus, it would be prudent to understand a range of fungicide-pathogen interactions and to utilize investigations on fungicide physical modes of action to optimize their use in disease management programs.

\section{ACKNOWLEDGMENTS}

We thank H. N. Burr and A. C. Lewis for their assistance in performing laboratory assays; J. A. Burr, L. E. Hoffman, and D. G. Riegel for project support and assistance; R. McDowell and G. Olaya for technical advice; and Professors W. Köller and M. Szkolnik for their insight and helpful suggestions.

\section{LITERATURE CITED}

1. Ammerman, E., Lorenz, G., Schelberger, K., Wenderoth, B., Sauter, H., and Rentzea, C. 1992. BAS $490 \mathrm{~F}-\mathrm{A}$ broad spectrum fungicide with a new mode of action. Pages 403410 in: Brighton Crop Protection Conference-Pests and Diseases-1992, vol. 1. Lavenham Press, Lavenham, Suffolk, UK.

2. Baldwin, B. C., Clough, J. M., Godfrey, C. R. A., Godwin, J. R., and Wiggins, T. E. 1996.

\section{$\square$ Azoxystrobin $\mathbf{\nabla}$ Mancozeb $\mathbf{M e t a l a x y l}$}

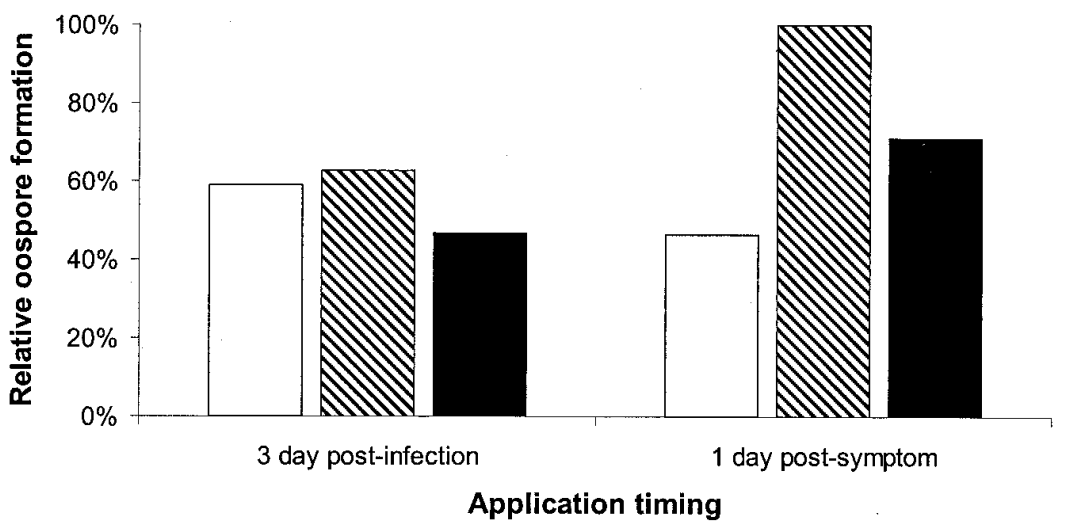

Fig. 5. Effects of azoxystrobin, mancozeb, and metalaxyl on Plasmopara viticola oospore formation. Vitis vinifera $\mathrm{cv}$. Riesling seedlings, inoculated with isolates DM-15 and AR-1, were treated with fungicides or $\mathrm{H}_{2} \mathrm{O} 3$ days after inoculation (postinfection) or 1 day after sporulation (postsymptom). Oospore formation was evaluated 14 days after sporangia production, following incubation at $12^{\circ} \mathrm{C}$. For each test, six individual seedlings were used for each fungicide treatment, with the test performed three times.

The discovery and mode of action of ICIA5504. Pages 69-78 in: Modern Fungicides and Antifungal Compounds. H. Lyr, P. E. Russell, and H. D. Sisler, eds. Intercept, Andover, Hants, UK.

3. Becker, W. F., Von Jagow, G., Anke, T., and Steglich, W. 1981. Oudemansin, strobilurin A, strobilurin B, and myxothiazole: New inhibitors of the $b_{1}$ segment of the respiratory chain with an E- $\beta$-methoxyacrylate system as a common structural element. FEBS Lett. 132:329-333.

4. Bissbort, S., Albert, G., and Schloesser, E. 1997. Effects of dimethomorph on the oospore formation of Plasmopara viticola. Z. Pflanzenkrankh. Pflanzenschutz 104:126-132.

5. Brandt, U., Schaegger, H., and Von Jagow, G. 1988. Characterization of binding of the methoxyacrylate inhibitors to mitochondrial cytochrome c reductase. Eur. J. Biochem. 173:499-506.

6. Godwin, J. R., Anthony, V. M., Clough, J. M., and Godfrey, C. R. A. 1992. ICI A5504, a novel broad spectrum systemic beta methoxyacrylate fungicide. Pages 435-442 in: Brighton Crop Protection Conference-Pests and Diseases-1992, vol. 1. Lavenham Press, Lavenham, Suffolk, UK.

7. Gold, R. E., Ammerman, E., Koehl, H., Leinhos, G. M. E., Lorenz, G., Speakman, J. B., Stark-Urnau, M., and Sauter, H. 1996. The synthetic strobilurin BAS 490 F: Profile of a modern fungicide. Pages 79-92 in: Modern Fungicides and Antifungal Compounds. $\mathrm{H}$. Lyr, P. E. Russell, and H. D. Sisler, eds. Intercept, Andover, Hants, UK.

8. Gold, R. E., and Leinhos, G. M. 1995. Fungicidal effects of BAS $490 \mathrm{~F}$ on the development of and fine structure of plant pathogenic fungi. Pestic. Sci. 43:250-253.

9. Heaney, S. P., and Knight, S. C. 1994 ICIA5504: A novel broad-spectrum systemic fungicide for use on fruit, nut and horticultural crops. Pages 509-516 in: Brighton Crop Protection Conference-Pests and Diseases1994, vol. 2. Major Print, Nottingham, UK.

10. Hewitt, W. B., and Pearson, R. C. 1988 Downy mildew. Pages 11-13 in: Compendium of Grape Diseases. R. C. Pearson and A. C. Goheen, eds. American Phytopathological Society, St. Paul, MN.

11. Jordan, D. B., Livingston, R. S., Bisaha, J. J. Duncan, K. E., Pember, S. O., Picollelli, M. A., Schwartz, R. S., Sternberg, J. A., and Xiao-Song, T. 1999. Mode of action of famoxadone. Pestic. Sci. 55:105-188.

12. Köller, W. 1994. Chemical control of apple scab-Status quo and future. Norw. J. Agric. Sci. S17:149-170.

13. Leinhos, G. M., Gold, R. E., Düggelin, M. and Guggenheim, R. 1997. Development and morphology of Uncinula necator following treatment with the fungicides kresoximmethyl and penconazole. Mycol. Res. 101:1033-1046.

14. Mitsuhiro, I., Michio, M., Hideyuki, T., Hasagawa, R., Ichiba, T., Yoshio, H., and Takeda R. 1999. Structural and fungicidal activities of methoxy-iminophenylacetamide derivatives. Pestic. Sci. 55:347-349.

15. Ronzon-Tran Manh Sung, C., and Clerjeau, M. 1988. Techniques for formation, maturation, and germination of Plasmopara viticola oospores under controlled conditions. Plant Dis. 72:938-941.

16. Sauter, H., Ammerman, E., Benoit, R., Brand, S., Gold, R. E., Grammenos, W., Köhl, H., Lorenz, G., Muller, B., Röhl, F., Schirmer, U., Speakman, J. B., Wenderoth, B., and Wingert, H. 1995. Mitochondrial respiration as a target for antifungals: Lessons learned from research on strobilurins. Pages 173-191 in: Antifungal Agents-Discovery and Mode of Action. G. K. 
Dixon, L. G. Copping, and D. W. Holloman, eds. BIOS, Oxford.

17. Szkolnik, M. 1981. Physical modes of action of sterol-inhibiting fungicides against apple diseases. Plant Dis. 65:981-985.

18. Von Jagow, G., Gribble, G. W., and Trumpower, B. L. 1986. Mucidin and strobilurin A are identical and inhibit electron transfer in the cytochrome bc-1 complex of the mitochondrial respiratory chain at the same site as myxothiazol. Biochemistry 25:775-780.

19. Wicks, T., and Lee, T. C. 1982. Evaluation of fungicides applied after infection for control of Plasmopara viticola on grapevine. Plant Dis. 66:839-841.

20. Wilcox, W. F., and Riegel, D. R. 1996. Evaluation of fungicides and spray timings for control of downy and powdery mildew of grapes, 1995. Fungic. Nematicide Tests 51:75.

21. Wilcox, W. F., and Riegel, D. R. 1997. Evaluation of fungicide programs for control of grapevine downy mildew, 1996. Fungic. Nematicide Tests 52:84-85.

22. Wilcox, W. F., and Riegel, D. R. 1998 Evaluation of fungicide programs for control of downy mildew and powdery mildew of grapevine, 1997. Fungic. Nematicide Tests 53:105-106.

23. Wilcox, W. F., Riegel, D. R., and Wong, F. P 1999. Evaluation of fungicide programs for control of grapevine downy mildew, 1998. Fungic. Nematicide Tests 54:111.

24. Wong, F. P., Burr, H. N., and Wilcox, W. F. 2000. Heterothallism in Plasmopara viticola (grapevine downy mildew). Phytopathology 90:S85.

25. Wong, F. P., and Wilcox, W. F. 2000 Distribution of baseline sensitivities to azoxystrobin among isolates of Plasmopara viticola. Plant Dis. 84:275-281.

26. Young, J. E., Hart, C. A., Saunders, J. A., and Godwin, J. R. 1998. Effects of azoxystrobin on infection development of the grapevine downy mildew pathogen, Plasmopara viticola. 7th Int. Congr. Plant Pathol. Edinburgh, Scotland, UK, 9-16 August 1998. On-line, publication 5.5.21.

27. Ypema, H. L., and Gold, R. E. 1999. Kresoxim-methyl: Modification of a naturally occurring compound to produce a new fungicide. Plant Dis. 83:4-19. 